\title{
Assessment of Bucco Lingual Width of Mandibular Bone in Molar Area in Relation to the Dental Status Using an Occlusal Film
}

\author{
Omar Basheer AL Tekreeti ${ }^{1}$, Alaa S Mahdi' ${ }^{2}$, AreejA Najm² ${ }^{2}$, Farah Abdul Salam Hadi' ${ }^{2}$, Bashar M Sakin Al Noorahchi ${ }^{3}$, \\ Zainab Alrufaye ${ }^{4}$ and Wisam W Alhamadi*5 \\ ${ }^{1}$ Department of Oral \& Maxillofacial Radiology, University of Tekreet, Iraq \\ ${ }^{2}$ Depatment of Oral \& Maxillofacial Radiology, University of Baghdad, Iraq \\ ${ }^{3}$ Department of Dentistry, Ministry of Health, Iraq \\ ${ }^{4}$ Department of Operative Dentistry, Specialized Dental Center, Iraq \\ ${ }^{5}$ Department Dentistry, University of Misan, Iraq

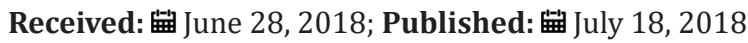 \\ *Corresponding author: Wisam W Alhamadi, Department Dentistry, University of Misan, Amara city, Iraq, Tel: +9647703378030; \\ Email: wisam.alhamadi@gmail.com
}

Abstract

Background: The alveolar process which is bearing of the teeth, tooth extraction is the common cause of alveolar ridge resorption, occlusal radiographical technique of the mandibular arch has the ability to determine the size of the outer and inner cortical bone of the mandible.

Aim of the Study: The aim of this study is to assist the bucco-lingual width of mandibular bone at molar area in relation to dental status in occlusal film.

Material and Method: 30 patients (15 dentulous and 15 edentulous) 18-25 years old, they were collected from popular clinic in Baghdad and referred to diagnosis department of Collage of Dentistry/ University of Baghdad. An occlusal film is placed into patient mouth, so that it is centered over molar area on the side to be radiographed. After exposure and film processing, a Varnier caliper is used to measure the width of bone.

Results: in SPSS statistic, by calculating the Mean, Stander Deviation and P-Value we found that the bone width of edentulous patients is less than the bone width of the dentulous patient in the posterior area of the mandible.

Conclusion: we concluded that the bone width of the edentulous patients is less than the bone width of dentulous patients in the posterior area of the mandible due to loss of mandibular molars.

Clinical Significance: These inevitably changes will affect the oral health and function, the dental team faces the challenge of creating a prosthetic restoration such as dentures or more importantly implants to compensate or eliminates these adverse effects. Sufficient alveolar bone volume and favorable architecture of the alveolar ridge are essential to obtain optimal functional and aesthetic prosthetic reconstructions.

Keywords: Resorption; Mandible; Occlusal Film; Dentulous; Edentulous; Varnier Caliper; Prosthetic; Aesthetic; Alveolar; Maxilla

\section{Introduction}

The mandible is the strongest, largest, and the lowest bone in the skull [1] simply the mandible composed of the body and two ram is above the basal bone of the mandible there is the alveolar process which is bearing of the teeth [2] alveolar process in the maxilla and mandible undergoes resorption due to loss of teeth, old age, systemic osteoporosis, hormone misbalance (Ca and P) metabolism disorder and gender [3]. Tooth extraction is the common cause of alveolar ridge resorption, after extraction the socket would heal quietly and it will be restored partially, the growth of bone inside the socket would be synchronized with alveolar ridge resorption, bone loss will be in horizontal and vertical direction and mainly obvious on the buccal aspect $[4,5]$ this process of alveolar ridge resorption will result in shorting and narrowing of the ridge [6]. The $1^{\text {st }}$ uses of clinical radiography was the intraoral radiography and it used since one century, to the present time it considered as the main non- invasive investigation method for the examination and evaluation of the osseous intraoral structures [7]. Occlusal radiographical technique of the mandibular arch has the ability to determine the size of the outer and inner cortical bone of the mandible [8]. The aim of this study is to assist the bucco-lingual width of mandibular bone at molar area in relation to dental status in occlusal film. 


\section{Material and Methods}

\section{Study Design}

This prospective study composed of 30 patient participants, ranging from 18-25 years old, they were carefully informed about the aim of the investigation and they were much cooperated, they were collected from popular clinic in Baghdad and referred to diagnosis department of College of Dentistry/ University of Baghdad, sample collection was from (12/2016 - 4/2017).

\section{The Samples Were Divided Into}

Dentulous Group: Included samples of 15 dentulous patients in the molar region of the lower jaw.

Edentulous group: Include samples of 15 edentulous patients in the molar region of the lower jaw.

\section{Criteria of Exclusions}

a) Patients with diseases that affect bone metabolism like Cushing syndrome, Paget's disease, osteogenesis imperfect, malabsorption, renal osteodystrophy, kidney transplantation, hyperparathyroidism, patients on corticosteroids, diabetes mellitus, radiation therapy and idiopathic osteoporosis.

b) Patients with retained roots in the molar region.

c) Patients with implants in the posterior area.

d) Patients wearing dentures in the posterior area.

\section{Materials}
a) Occlusal film
b) Vernier caliper
c) X-Ray machine (Max 70), (70 Volt, 10 Amber)
d) Dental mirrors
e) Masks and gloves

\section{Methods}

"Prior to starting to take films, the patient must be positioned properly. Seat the patient and ask them to remove their glasses and any removable partial dentures or orthodontic appliances. Adjust the headrest to support the head while taking films. Raise or lower the chair to a comfortable height for the operator. Place the lead apron and thyroid collar on the patient (Figures 1-3). Position the head so that the occlusal plane of the mandibular teeth is 45 degrees to the horizontal plane and the median plane of the face is vertical. A film is placed into the patient's mouth, so that it is centered over the molar teeth on the side to be radiographed Adjust the tube so that the central ray will pass from below the mandible and through the molar region at a perpendicular angle to the plane of the film packet. The patient is instructed to hold still while maintaining the correct position. The operator leaves the room where he or she will press a button, to expose the film, which produces an audible beep. The operator re-enters the operatory and removes the film from the patient's mouth [9].

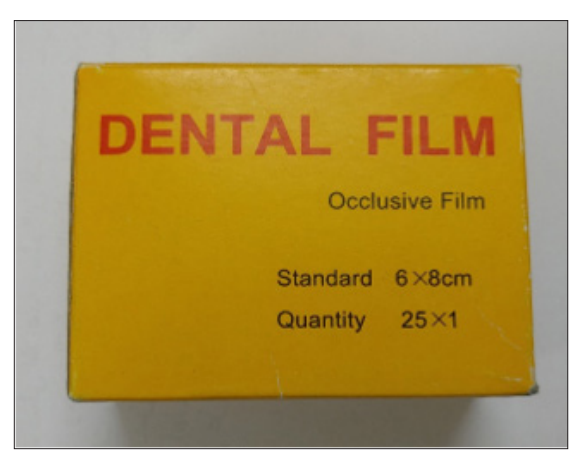

Figure 1: Occlusal Films Package.

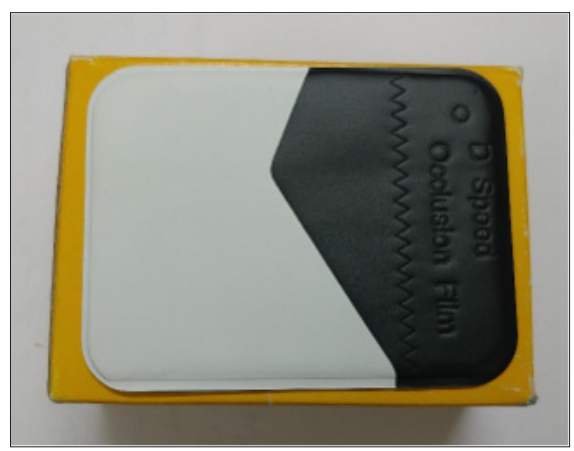

Figure 2: The Occlusal Film.

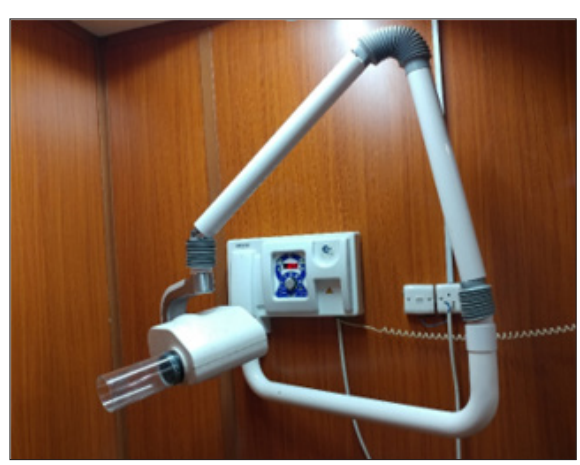

Figure 3: The Occlusal Film.

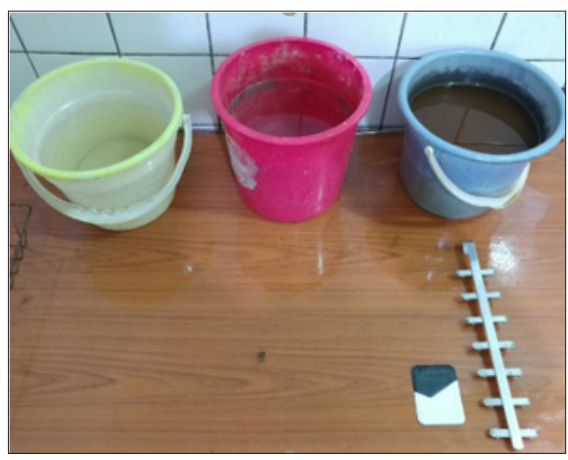

Figure 4: The Processing Room.

As illustrated in the text book (oral radiology principles and interpretation) Following film processing (Figure 4) the films were examined, the films were assessed to determine whether all areas can be visualized adequately. Anatomical variations, as well as local 
restorations may obscure the image so that all the required areas cannot be clearly seen, necessitating a re-take of that film. Using Vernier caliper (Figures 5 \& 6) on zero level to measure the width of the bone, for the dentulous patients we put the arms of the Vernier on the buccal and the lingual cortical plates of the lower first molar and the measurements are taken, for the edentulous patient the position of the missing lower first molar is estimated depending on the landmarks and/or remaining teeth, and the measurements taken by putting the arms of the Vernier on the buccal and the lingual cortical plates, then these measurements are noted.

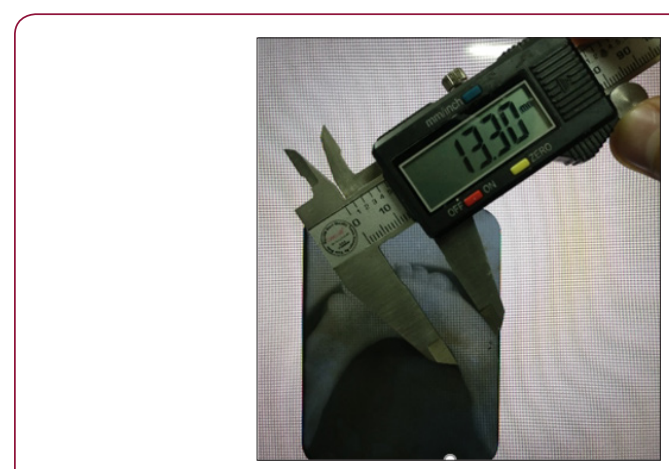

Figure 5: Taking Measurements.

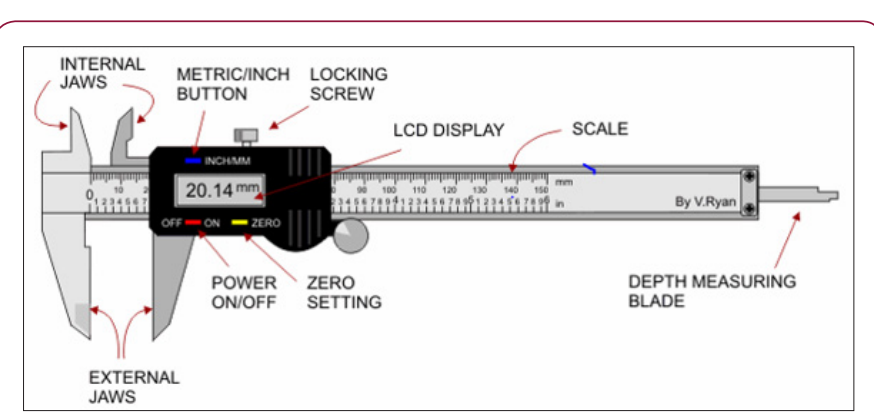

Figure 6: The digital Vernier caliper.

\section{Result}

Table 1: The numerical values of the 2 groups.

\begin{tabular}{|c|c|}
\hline Group 1 (Dentulous) & Group 2 (Edentulous) \\
\hline 14.76 & 14.76 \\
\hline 15.81 & 15.81 \\
\hline 15.34 & 15.34 \\
\hline 14.86 & 14.86 \\
\hline 13.68 & 13.68 \\
\hline 13.16 & 13.16 \\
\hline 13.6 & 13.6 \\
\hline 13.93 & 13.93 \\
\hline 14.26 & 14.26 \\
\hline 12.53 & 12.53 \\
\hline 13.41 & 13.41 \\
\hline 15.06 & 15.06 \\
\hline 11.79 & 11.79 \\
\hline 13.4 & 13.4 \\
\hline 12.65 & 12.65 \\
\hline & \\
\hline
\end{tabular}

In SPSS statistics "bone width in the posterior aria of the mandible" were entered under the variable name (Measurements) and we separated the groups by creating a grouping variable called "Group 1" for the edentulous and "Group 2" for the dentulous as in Table 1 From the table above we notice that the Mean for group 1 "Dentulous" is (13.8827) and the Mean for group 2 "Edentulous" was (11.4733) as seen in Table 2 So, we concluded that the bone width of dentulous patients is less than the bone width of edentulous in the posterior area of the mandible. Using test Mann Whitney U Test there was significance difference between "dentulous" and "edentulous" groups as seen in Table 3.

Table 2: The Mean, Std. Deviation, Median of the 2 groups.

\begin{tabular}{|c|c|c|c|c|}
\hline Group & Mean & N & Std. Deviation & Median \\
\hline A & 13.8827 & 15 & 1.13144 & 13.6800 \\
\hline B & 11.4733 & 15 & .82572 & 11.4800 \\
\hline Total & 12.6780 & 30 & 1.56474 & 12.4650 \\
\hline
\end{tabular}

Table 3: Test summary.

\begin{tabular}{|c|c|c|c|}
\hline Null Hypothesis & Test & Sig. & Decision \\
\hline $\begin{array}{c}\text { The distribution of } \\
\text { width is the same } \\
\text { across categories of } \\
\text { group }\end{array}$ & $\begin{array}{c}\text { Independent } \\
\text { samples Mann- } \\
\text { Whitney U test }\end{array}$ & .0001 & $\begin{array}{c}\text { Reject the null } \\
\text { hypothesis }\end{array}$ \\
\hline
\end{tabular}

Note: Asymptotic Significances are displayed. The significance level is .05. Exact significance is displayed for this test.

\section{Discussion}

The development of the alveolar process would be in conjunction with teeth eruption, so, as a result of teeth removal, atrophy of the alveolar process would be occurred [10-12] previous bone loss because of endodontic lesion, periodontal disease, or trauma would complicate the resorption of bone after teeth removal [13] cephalometric measurement, radiographic analysis, study cast measurement can describe the changes in the morphology of extraction socket [14]. The study was in agreement with Van et al. [15] whom studied the dimensional changes of the alveolar process of post-extraction sockets in humans both clinically and radiographically [15] and in agreement with Desai et al. [16] they determine the dimensions of ridge width of bone and deviation of center of ridge in the mandibular jaw using intraoral true occlusal projection as a pre-prosthetic diagnostic method [16].

\section{Conclusion}

We concluded that the bone width of the edentulous patients is less than the bone width of dentulous patients in the posterior area of the mandible due to loss of mandibular molars.

\section{Clinical significance}

These inevitably changes will affect the oral health and function, the dental team faces the challenge of creating a prosthetic restoration such as dentures or more importantly implants to compensate or eliminates these adverse effects. Sufficient alveolar bone volume and favorable architecture of the alveolar ridge are 
essential to obtain optimal functional and aesthetic prosthetic reconstructions.

\section{References}

1. Gray's Anatomy. The Anatomical Basis of Clinical Practice $\left(40^{\text {th }} \mathrm{Edn}\right) \mathrm{p}$. 530.

2. Marius Pricop, Horațiu Urechescu, Adrian Sîrbu (2012) Fracture of the mandibular coronoid process case report and review of literature Revchiroromaxilofac Implantol.

3. Daroszewska A, Vant Hof RJ, Rojas JA, Layfield R, Landao Basonga E, et al (2011) A point mutation in the ubiquitin associated domain of SQSMT1 is sufficient to cause a Paget's disease-like disorder in mice. Hum Mol Genet 20(14): 2734-2744.

4. Lekovic V, Camargo PM, Klokkevold PR, Weinlaender M, Kenney EB, et al. (1998) Preservation of alveolar bone in extraction sockets using bioabsorbable membranes. Journal of Periodontology 69(9): 10441049.

5. Araujo MG, Lindhe J (2005) Dimensional ridge alterations following tooth extraction. An experimental study in the dog. Journal of Clinical Periodontology 32(2): 212-218.

6. Pinho MN, Roriz VL, Novaes AB, Taba M, Grisi, et al. (2006) Titanium membranes in prevention of alveolar collapse after tooth extraction. Implant Dentistry 15(1): 53-61.

7. Matteson SR, Deahl ST, Alder ME, Nummikoski PV (1996) Advanced Imaging Methods. Crit Rev Oral Biol Med. 7(4): 346-395.

8. Miloro M, Ghali GE, Larsen EP, Waite DP (2004) Implant Prosthodontics. Peterson's Principles of Oral and Maxillofacial Surgery. ( $2^{\text {nd }}$ edition.), BC Decker Inc, London, UK, 62(1): 89.

\section{ISSN: 2574-1241}

DOI: 10.26717/BJSTR.2018.07.001439

Wisam W Alhamadi. Biomed J Sci \& Tech Res

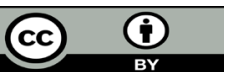

This work is licensed under Creative Commons Attribution 4.0 License

Submission Link: https://biomedres.us/submit-manuscript.php
9. Stuart C White, Michael J Pharoah (2009) Oral Radiology principles and interpretation ( $6^{\text {th }}$ Edn.).

10. Atwood DA (1957) A cephalometric study of the clinical rest position of the mandible Part II The variability in the rate of bone loss following the removal of occlusal contacts. Journal of Prosthetic Dentistry 7(4): 544-552.

11. Hedega ${ }^{\circ}$ rd B (1962) Some observations on tissue changes with immediate maxillary dentures. Dental Practitioner 13: 70-78.

12. Tallgren A, Odont (1972) The continuing reduction of the residual alveolar ridges in complete denture wearers: a mixed longitudinal study covering 25 years. Journal of Prosthetic Dentistry 27(2): 120-132.

13. Iasella JM, Greenwell H, Miller RL, Hill M, Drisko C, et al. (2003) Ridge preservation with freeze-dried bone allograft and a collagen membrane compared to extraction alone for implant site development: a clinical and histologic study in humans. Journal of Periodontology 74(7): 990999.

14. Chen ST, Wilson TG, Hammerle CH (2004) Immediate or early placement of implants following tooth extraction: review of biologic basis, clinical procedures and outcomes. International Journal of Oral and Maxillofacial Implants 19: 12-25.

15. Van Der Weijden F, Dell Acqua F, Slot DE (2009) Alveolar bone dimensional changes of post-extraction sockets in humans : a systematic review. J Clin Periodontol 36(12): 1048-1058.

16. Deasi SR, Karthikeyan I, Singh R (2013) An in Office, Cost Effective Technique for Measuring Width of Bone Using Intra-Oral Periapical Radiographs in Occlusal Projection. J Ind Soc Periodontol 17(1): 82-86.

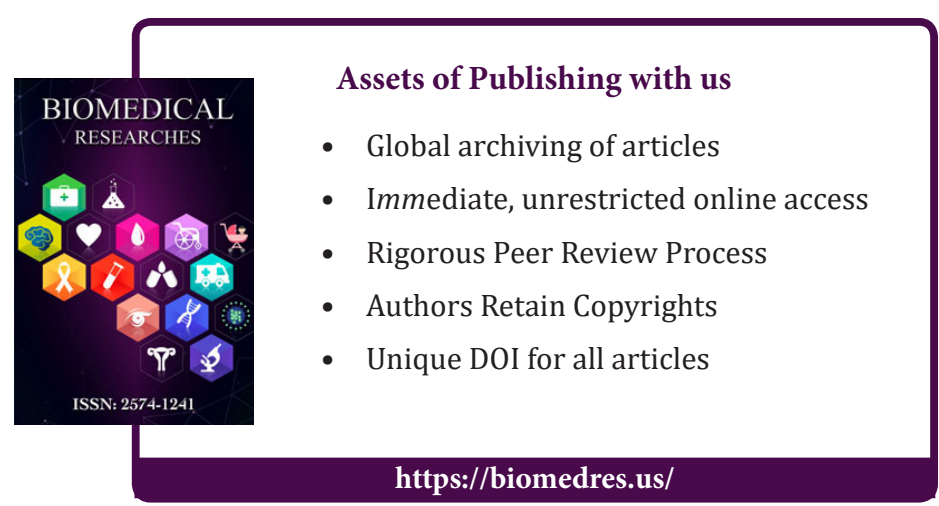

